\title{
Nutritional Status, Characterization and Fatty Acid Composition of Oil and Lecithin Isolated from Fresh Water Fish Shoul (Channa striata)
}

\author{
Md. Rasel Molla, A. K. M. Asaduzzaman, Md. Abdur Rashid Mia, Meftah Uddin, \\ Shahangir Biswas, Md. Salim Uddin * \\ Department of Biochemistry and Molecular Biology, Rajshahi University, Rajshahi, Bangladesh
}

Email address:

msuddin75@yahoo.com (Md. S. Uddin)

\section{To cite this article:}

Md. Rasel Molla, A. K. M. Asaduzzaman, Md. Abdur Rashid Mia, Meftah Uddin, Shahangir Biswas, Md. Salim Uddin. Nutritional Status, Characterization and Fatty Acid Composition of Oil and Lecithin Isolated from Fresh Water Fish Shoul (Channa striata). International Journal of Nutrition and Food Sciences. Vol. 5, No. 1, 2016, pp. 9-15. doi: 10.11648/j.ijnfs.20160501.12

\begin{abstract}
Fishes are rich sources of different types of nutrients. Some species are found in marine water; on the other hand some varieties are available in fresh water. Consumption of fish is very beneficial to the health and development of the human body and fish becomes an integral part of the food culture of populations in many countries. They provide essential nutrients to the human. The aim of this study was to estimate the nutritional status of the selected fish species, to extract and characterize the fish oil and lecithin. Fish oil contains higher amount of polyunsaturated fatty acids which have significant effect in maintaining a healthy cardiac life. Biochemical composition of shoul (Channa striata) was determined. It was found that fishes are rich sources of protein and other nutrients. All the other parameters such as, moisture, protein, lipid, total sugar and ash were found in significant amount in shoul. Shoul fish oil was extracted using n-hexane by soxhlet apparatus. The percentage of oil from shoul fish powder was $12.64(\mathrm{~g} \% \mathrm{w} / \mathrm{w})$. Lecithin was also extracted from this fish fleshes before and after oil extraction. Lecithin was $2.07(\mathrm{~g} \% \mathrm{w} / \mathrm{w})$ and $3.10(\mathrm{~g} \% \mathrm{w} / \mathrm{w})$ before and after oil extraction. It was found that percentage of lecithin was increased after oil extraction. The physicochemical properties of fish oil and lecithin were investigated. The higher saponification value and iodine value indicates that oil and lecithin contains shorter fatty acid chain length with lower molecular weight and the presence of higher amounts of unsaturated fatty acids in the samples. Low acid value and peroxide value indicate higher quality index of fish oil and lecithin. The oxidative stability of shoul fish lecithin was also measured by thiocyanate (TC) method and thiobarbituric acid (TBA) method. Shoul fish lecithin showed higher oxidative stability due to the presence of natural antioxidant. Fatty acid composition of shoul fish oil and lecithin was measured by gas chromatography (GC). The important polyunsaturated fatty acids eicosapentaenoic acid (EPA) and docosahexaenoic acid (DHA) were found to be $0.49 \%$ and $1.37 \%$ in fish oil. But lecithin contains only $7.8 \%$ DHA and other monounsaturated fatty acids. This fish oil and lecithin also contain higher amount of monounsaturated fatty acid and average amount of polyunsaturated fatty acids. Fish oil and lecithin also act as sources of essential fatty acid. Therefore, we can use this fish oil and lecithin in edible purpose, food industry and pharmaceutical industry.
\end{abstract}

Keywords: Fish Oil, Lecithin, Fatty Acid Compositions, Oxidative Stability, Shoul

\section{Introduction}

One of the major sectors of agriculture is represented by the fisheries sector, because fish becomes an integral part of the food culture of populations in many countries. The composition of the fish including protein, lipid and the contribution of micronutrients, especially vitamin $\mathrm{A}$ and mineral from different types of fish species have been focused at the end of last century [1]. In recent years, researchers are interested on the different bioactive compounds including polyunsaturated fatty acids, phospholipids, lecithin, peptides and pigments obtained from various fish species especially from marine fishes [2]. There is strong evidence that consumption of fish containing high levels of polyunsaturated fatty acid is favorable for human health [3, 4]. Polyunsaturated fatty acids and lipid soluble bioactive compounds have been attracted much attention for 
health benefits. There is commercial interest in obtaining polyunsaturated fatty acids, in particular eicosapentaenoicacid (EPA) and docosahexaenoic acid (DHA), because these $\omega-3$ fatty acids are potential in the prevention of human diseases, such as in lowering blood cholesterol and thus preventing heart diseases. It is also known that $\omega-3$ fatty acids are essential for normal growth and development and may play an important role in the prevention and treatment of coronary artery disease, hypertension, arthritis, others inflammatory and autoimmune disorders and cancer [5]. Fish oil is important not only for their application in food, but also for industrial applications, such as the production of pharmaceuticals, cosmetics, paints and so more. Fish oil is composed of triglycerides containing polyunsaturated fatty acids, most notably EPA and DHA. Fish and fish oils contain long-chain polyunsaturated omega-3 fatty acids, more specifically, eicosapentaenoic acid (EPA) and docosahexaenoic acid (DHA) [6]. Fish and other marine life are rich sources of a special class of polyunsaturated fatty acids known as the omega- 3 or $n-3$ fatty acids $[7,8]$. The researchers conclude that regular consumption of oil-rich fish substantially reduces the level of circulating plateletmonocyte aggregates and through this mechanism may help to prevent atherosclerosis and thrombosis [9]. Lecithin is a sticky fatty substance composed mainly of phospholipid mixtures especially phosphatidylcholine (PC) and phosphatidylethanolamine (PE) with small amount of glycerides, neutral lipids, and other suspended matter [10]. Lecithin from egg yolk, plant tissues and animal are usually utilized for its emulsifying, dispersing and stabilizing properties in the food, pharmaceutical and cosmetic industries. Pharmacologically, the lecithin is used in the treatments for hypercholesterolemia, neurologic disorders, liver ailments, and intramuscular and intravenous injectable and parenteral nutrition formulations [11]. The application of lecithin is also recognized to modify the immune system by activating specific and nonspecific defense systems. Soybeans and egg yolk are the main commercial sources of lecithin $[12,13]$. In soybean lecithin, unsaturated fatty acids are present in very low percentage as compared to saturated fatty acids. Moreover, lecithin from soybeans does not contain $\omega-3$ fatty acids, eicosapentaenoic acid (EPA) and docosahexaenoic acid (DHA). In nutritional supplements, egg phospholipids cannot also play a significant role because they have a relatively high cholesterol level and unfavorable fatty acid profiles [14-15]. The importance of lecithin analysis is to find the quality index, properties, fatty acid composition, immunologic and neurologic function. As a result, we can use lecithin according to the functional properties of lecithin. Recent studies suggest that a lecithin enriched diet can modify the cholesterol homeostasis and lipoprotein metabolism. Lecithin diet modifies the cholesterol homeostasis in the liver, increasing the activity of 3-hydroxy-3 methylglutaryl coenzyme A reductase (HMGCoA) reductase and cholesterol 7 alpha-hydroxylase and decreasing the microsomal acyl CoA: cholesterol acyltransferase (ACAT) activity. One of the most spectacular properties of lecithin is its ability to reduce the excess of LDL cholesterol. It also promotes the synthesis in the liver of great amount of HDL, the beneficial cholesterol. Bile acid secretion with high levels of cholesterol and phospholipids is encouraged by lecithin-rich diets when compared with diets without lecithin. Lecithin contains choline that is used in treatment of neural disorder. Lecithin is one of the nature elements that have dispersing properties. That is why it can emulsify fat, avoiding its absorption [13-15]. Most of the research work has been carried out to extract oil mainly from marine fishes. On the other hand, very few studies have been performed on the extraction of lecithin from fish sources. Bangladesh is a densely populated country and more than ninety percent people depend on the fresh water fishes. In Bangladesh, the main sources of fresh water fishes are ponds, haors, beel and rivers where shoul are available as wild fish. Based on the consideration in increasing demand of the functional foods.

\section{Materials and Methods}

\subsection{Materials}

The fresh shoul fish were collected from local market of Rajshahi, Bangladesh.

\subsection{Sample Preparation}

The fish fleshes were separated from bone and were sundried for about 72 hours. The sun-dried fleshes were then grinded by mechanical grinder and stored at $-20^{\circ} \mathrm{C}$ until further analysis. Then, oil was extracted from both fishes by Soxhlet extraction apparatus using $\mathrm{n}$-hexane and stored at $4^{\circ} \mathrm{C}$ for further analysis. Lecithin's were extracted from fish powder according to the method of Palacios and Wang (2005) [16] modified by Uddin [12].

\subsection{Extraction of Oil from Shoul Fish}

The extraction of oil was carried out in a Soxhlet apparatus using n-hexane as solvent. Oil, triglyceride portion of shoul fishes was extracted by suitable solvents under the operating condition. Continuous Soxhlet extraction apparatus was used for the extraction of oil (Suter et al., 1986) [17]. About 60-70 gm of sun dried powder from shoul fishes was placed into the extraction thimble and the extraction was run about 5-6 hours until the colour of the condensed solvent at the top of the apparatus was clear. The solvent was evaporated at low temperature (almost ambient temperature) and the fish oil was stored at $4^{\circ} \mathrm{C}$ temperature.

\subsection{Isolation of Lecithin}

Lecithin's were extracted from stored fish powder and Soxhlet extracted residues according to the method of Palacios and Wang [16] modified by Uddin [12]. In briefly, $100 \mathrm{ml}$ of ethanol (95\%) was added to $30 \mathrm{~g}$ of fish powder residues and stirred for almost 12 hours by a magnetic stirrer. The mixture was then centrifuged at $6000 \mathrm{rpm}$ for $10 \mathrm{~min}$. 
The supernatant that contained mainly polar lipids with very low amounts of neutral lipids was collected in a separatory funnel. The precipitate of residue was further extracted with $100 \mathrm{ml}$ of ethanol $(95 \%)$ and followed centrifugation, the supernatant was added to the previous ethanol extract. Twice volume of hexane was added to the ethanol extract for separating the neutral lipids from the polar lipids. The ethanol phase was then collected and evaporated at $40^{\circ} \mathrm{C}$. The remaining lipid residue was dissolved in hexane. A fifth volume of chilled acetone $\left(4^{\circ} \mathrm{C}\right)$ to hexane was added to the hexane mixture with slow stirring for precipitation of the gummy material. The mixture was placed in an ice bath for $15 \mathrm{~min}$ and then centrifuged at $5000 \mathrm{rpm}$ for $10 \mathrm{~min}$. The collected precipitate called fish lecithin was stored at $-20^{\circ} \mathrm{C}$ until further analysis.

\subsection{Characterization of Fish Oil and Lecithin}

The iodine value of oil and lecithin was measured by the method of Hanus [18]. The iodine value of fat or oil is the amount of halogen absorbed under specific conditions and is expressed as the number of grams of iodine per 100 grams of fat or oil. Saponification value was measured by IUPAC [19]. The saponification value of the fat or oil is the number of milligrams of potassium hydroxide required to saponify completely $1 \mathrm{~g}$ of fat or oil. The saponification value is related to the molecular weight of fat or oil and therefore provides information on the mean molecular weight of the combined fatty acids. The acid value was measured according to the official method of IUPAC [19]. The acid value was the amount of milligrams of $\mathrm{KOH}$ required to neutralize the acids present in $1 \mathrm{~g}$ of sample. Peroxide value was determined by the method of AOCS [20]. The peroxide value is defined as the milliequivalent of peroxide oxygen combined in a kilogram of oil.

\subsection{Determination of Fatty Acid Composition by Gas Chromatography (GC)}

GC analysis was performed to determine the fatty acid compositions of oil and lecithin from shoul fish. A Hewlett Packard gas chromatograph (6890 Series II GC system) with a fused silica capillary column (100 m length x 0.25 $\mathrm{mm}$ internal diameter, $0.2 \mu \mathrm{m}$ of film, Supelco, Bellefonte, Pennsylvania, USA) was used. The fatty acid methyl esters were firstly prepared according to the AOCS official method of Ce 2-66 (AOCS) [20]. Nitrogen was used as the carrier gas $(1 \mathrm{~mL} / \mathrm{min})$ of the fatty acid methyl esters. The oven temperature was programmed according to Uddin [12]. The initial temperature, $130^{\circ} \mathrm{C}$ was constant for $3 \mathrm{~min}$ and then increased to $240^{\circ} \mathrm{C}$ at a rate of $4^{\circ} \mathrm{C} / \mathrm{min}$ followed by a hold at $240^{\circ} \mathrm{C}$ for $10 \mathrm{~min}$. Temperature both for injector and detector were $250^{\circ} \mathrm{C}$. Fatty acid methyl esters were identified by comparison of retention time and standard fatty acid methyl esters mixtures (Supelco, Pennsylvania, USA).

\subsection{Oxidative Stability of Fish Lecithin}

To measure the oxidative stability, emulsions of lecithin in water were oxidized at $37^{\circ} \mathrm{C}$. Three emulsions of lecithin in water $(\mathrm{w} / \mathrm{w})$ (linoleic acid $4 \%$, lecithin $1 \%$, water $95 \%$; lecithin $5 \%$, water $95 \%$; $\beta$-carotene $1 \%$, lecithin $4 \%$, water $95 \%$ ) were prepared. Deionized and degassed water were used for emulsion preparation. The mixture was properly homogenized by a homogenizer. The oxidative stability of fish lecithin was measured by using linoleic acid and $\beta$ carotene as standard. Oxidative stabilities were checked by the thiocyanate (TC) and thiobarbituric acid (TBA) methods, which were used to measure the antioxidant activity [12, 2122]. In this study, these two methods were performed to measure the quality of the extracted lecithin in terms of its oxidative stability.

\subsubsection{Thiocyanate Method (TC Method)}

The oxidative stability of fish lecithin was measured by using the method of Mitsuda [21]. The peroxide formed by lipid peroxidation reacted with ferrous chloride and formed ferric ions. Ferric ions then combined with ammonium thiocyanate and produced ferric thiocyanate. In briefly, $0.1 \mathrm{ml}$ of emulsion solution was added to $4.7 \mathrm{ml}$ of $75 \%$ ethanol and $0.1 \mathrm{ml}$ of $30 \%$ ammonium thiocyanate. Then $0.1 \mathrm{ml}$ of $0.02 \mathrm{M}$ ferrous chloride in $3.5 \% \mathrm{HCl}$ was added to the reaction mixture. Exactly, 3 min after addition, the absorbance of a red color was measured at $500 \mathrm{~nm}$. The absorbance was recorded at 120 hours' intervals during the incubation.

\subsubsection{Thiobarbituric Acid Method (TBA Method)}

The oxidative stability of fish lecithin was measured by using the method of Ottolenghi [22]. The extent of lipid peroxidation was evaluated by TBA method. Malonadehyde, the product of lipid breakdown caused by oxidative stress, binds with TBA to form a red complex of thiobarbituric acid reactive substance (TBARS). In briefly, $2 \mathrm{ml}$ of $20 \%$ trichloroacetic acid and $2 \mathrm{ml}$ of $0.67 \%$ 2-thiobarbituric acid were added to $1 \mathrm{ml}$ of emulsion solution. The mixture was heated at $100^{\circ} \mathrm{C}$ for $10 \mathrm{~min}$ in a boiling water bath. After cooling, the mixture was centrifuged at $3000 \mathrm{rpm}$ for $20 \mathrm{~min}$. Absorbance of the supernatant containing TBARS was measured at $532 \mathrm{~nm}$.

\section{Results and Discussion}

\subsection{Nutritive value of Shoul Fish}

The mean percentage of moisture, protein, fat, carbohydrate contents and ash of shoul fish are showed in Table 1. The nutrient content of shoul (Channa striata) was determined. It was found that fishes are rich sources of protein and other nutrients. The percentage of moisture was $74.86 \pm 0.66$ for shoul. On the other hand, protein and lipid content of shoul was $15.31 \pm 0.61$ and $1.33 \pm 0.03$. All the other parameters such as, total sugar and ash were $0.04 \pm 0.01$ and $1.15 \pm 0.07$ in shoul. The protein content of shoul fish was higher than of boal fish [23]. 
Table 1. The nutrient content of shoul fish.

\begin{tabular}{ll}
\hline Parameters & Shoul \\
\hline Moisture (g \%) & $74.86 \pm 0.66$ \\
Total protein (g \%) & $15.31 \pm 0.61$ \\
Total lipid (g \%) & $1.33 \pm 0.03$ \\
Water soluble protein (g \%) & $1.52 \pm 0.06$ \\
Glycogen (g \%) & $1.11 \pm 0.01$ \\
Total soluble sugar (g \%) & $0.04 \pm 0.01$ \\
Non reducing sugar (g \%) & $0.03 \pm 0.01$ \\
Reducing sugar (g \%) & $0.01 \pm 0.1$ \\
Ash (g \%) & $1.15 \pm 0.07$ \\
\hline
\end{tabular}

All data are presented by mean value of 2 replicate \pm SD (SD was mentioned at least 0.01 ).

\subsection{Characterization of Oil}

The oil obtained from shoul flesh powder by Soxhlet extraction using n-hexane was approximately $0.12 \mathrm{~g}$ g- 1 fish powder. The lipid content of shoul flesh powder was lower than that of marine fishes. Table 2 shows the iodine value, percentage of FFA content, acid value, peroxide value and saponification value of fish oil. These parameters provide the quality index of the fish oil. The saponification value of shoul fish oil was $146.94 \pm$. The saponification value of Ajiaji fish oil is higher than Menhaden oil which is $259.5 \pm 2.0$ and 180.9 \pm 2.0 , respectively. This value indicates that Aji-aji fish oil contains shorter fatty acid chain length with lower molecular weight compared to Manhaden oil [24]. The iodine values of shoul fish oil were found to be $110.85 \pm 0.18$. These values were lower as compared to marine fishes but higher to fresh water fishes [25]. Iodine value has been determined to estimate the degree of unsaturation and the relative amounts of unsaturated fatty acids in the triglyceride molecules. The high iodine values of shoul fish oil indicate the presence of higher amounts of unsaturated fatty acids in the samples. Iodine value gives an estimation of the degree of unsaturation and the relative amounts of unsaturated fatty acids in the triglyceride molecules of the fat. It may be suggested that the oil under investigation contains higher amounts of unsaturated fatty acids as its iodine value was calculated to be 96.17 . A higher percentage of free fatty acid (above 1.5\%) is a determination or indication of unsuitability of the oil for edible purpose. So the fish oil of $M$. vittatus might be suitable for edible purposes as it contains free fatty acid less than $1.5 \%$.

Table 2. Chemical characteristics of the oil and lecithin obtained from shoul fish.

\begin{tabular}{lll}
\hline Parameters & Shoul fish oil & Shoul fish lecithin \\
\hline Saponification value $(\mathrm{mg} \mathrm{KOH} / \mathrm{g})$ & $146.94 \pm 0.88$ & $108.04 \pm 1.96$ \\
Iodine value $(\mathrm{mg} \mathrm{I} / \mathrm{g}$ oil) & $110.85 \pm 0.18$ & $76.28 \pm 1.47$ \\
Acid value $(\mathrm{mg} \mathrm{KOH} / \mathrm{g})$ & $13.95 \pm 0.04$ & $7.90 \pm 0.91$ \\
Peroxide value $\left(\mathrm{meq} \mathrm{O}_{2} / \mathrm{Kg}\right)$ & $7.91 \pm 0.01$ & $2.56 \pm 0.62$ \\
Percent of free fatty acid $(\%)$ & $7.01 \pm 0.53$ & $4.29 \pm 0.45$ \\
Specific gravity & $0.87 \pm 0.01$ & \\
\hline
\end{tabular}

All data are presented by mean value of 2 replicate \pm SD (SD was mentioned at least 0.01).

In this study, $12.64 \%(\mathrm{w} / \mathrm{w})$ oil was isolated from shoul fish powder. The percentages of oil from shoul are shown in
Fig 1. Iodine value, percentage of FFA content, acid value, peroxide value and saponification value of fish oil are given in Table 2. These parameters provide the quality index of the fish oil and lecithin. The iodine values were found to be $110.85 \pm 0.18$. These values were higher than the values of 83.23 for Channa marulius fish oil [26]. The higher degree of unsaturation i. e. the higher iodine value, the greater is the liability of the oil or fat to become rancid by oxidation [27]. The comparatively high saponification values indicate the presence of low proportion of lower fatty acids. The saponification value was found to be $146.94 \pm 0.88$ for shoul fish oil. Acid value is the measurement of free fatty acids present in the oils or fats. From investigation, the acid value of shoul fish oil was found to be $13.95 \pm 0.04$. The percentage of free fatty acid of shoul fish oil calculated from acid value was $7.01 \pm 0.53$. The acid value of 6.72 and percentage of free fatty acid of 3.38 for Tilapia fish oil were reported by Kadir [28]. Peroxide value is the milligram equivalents of peroxide oxygen combined in a kilogram of oil and peroxide value of oil is used as a measurement of rancidity which occurs by autoxidation. The peroxide value of shoul fish oil was $7.91 \pm 0.01$. This value was higher than the value of 2.5 for Aji-aji fish oil [24].

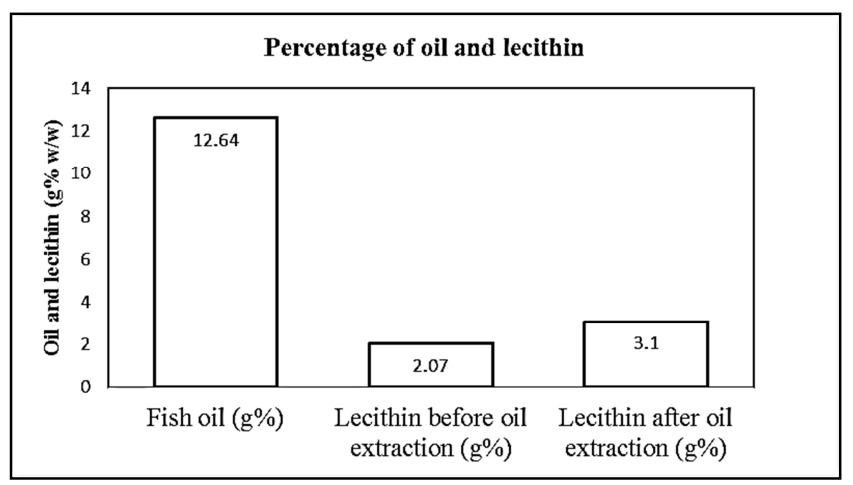

Figure 1. Soxhlet extraction of oil and isolation of lecithin before and after oil extraction.

\subsection{Characterization of Lecithin}

The percentage of lecithin from shoul is shown in Fig 1. Before and after oil extraction lecithin was found to be $2.07 \%$ and $3.10 \%$, respectively. These result showed that, the percentage of lecithin was increased after extracting oil from shoul fish powder. The amount of lecithin from squid viscera was $4.25 \%$ [12]. Iodine value, saponification value, percentage of FFA content, acid value and peroxide value are presented in Table 2. The saponification value of shoul fish lecithin was $108.04 \pm 1.96$. Saponification value is directly related to the chain length of fatty acids. Higher saponification value indicates the presence of low molecular weight fatty acid in triglyceride. Iodine values give an estimation of the amount of unsaturated fatty acids in the triglyceride molecules. Iodine value determines the degree of unsaturation of fat or oil. The iodine values were measured by the Hanus method and were found to be $76.28 \pm 1.47$ for shoul. The acid value was used to determine 
the acidity of the lecithin. Due to the presence of moisture in lecithin, FFA may be liberated by its hydrolytic rancidity. Determination of FFA content therefore provided an index of the quality of the fish lecithin. From investigation, the acid value of the shoul fish lecithin was found to be $7.90 \pm 0.91$. The percentage of free fatty acid of shoul fish calculated from acid value and was found to be $4.29 \pm 0.45$. Acid value was used to measure the quality index of lecithin. The lower acid value of shoul fish lecithin indicated the higher quality of product. The acid value of this fish was much lower than the value of 33.10 for squid viscera [12]. The acid values of food grade lecithin recommended by $\mathrm{FAO} / \mathrm{WHO}$ are found to be up to $36 \mathrm{mg}$ $\mathrm{KOH} / \mathrm{g}$ of lecithin [29]. Peroxide value is used for the measurement of rancidity which occurs by auto oxidation. Peroxide value is also used as quality index of lecithin. Peroxide value of shoul fish lecithin is shown in Table 2. Peroxide value of shoul fish lecithin was found to be 4.26 . The peroxide values of food grade lecithin recommended by FAO/WHO are found to be up to 10 milliequivalent/1000 g [29].

\subsection{Fatty Acid Compositions of Shoul Fish Oil and Lecithin}

The fatty acid compositions of shoul fish oil and lecithin obtained by GC are shown in Table 3. The percentages of the total polyunsaturated fatty acid in oil and lecithin were $12.34 \%$ and $16.70 \%$, respectively. The percentages of total unsaturated fatty acid were $42.71 \%$ and $45.10 \%$ in shoul fish oil and lecithin, respectively. Total monounsaturated fatty acid was found to be $39.71 \%$ and $38.20 \%$ in oil and lecithin. In oil the important polyunsaturated fatty acids EPA and DHA were found to be $0.49 \%$ and $1.37 \%$, respectively. These values were lower than the value of 7.7\% EPA and 14.5\% DHA for Salmon fish oil [24]. But lecithin contains only 7.80\% DHA which is lower than $14.5 \%$ of squid viscera lecithin [12]. Among the monounsaturated fatty acids, C18: 1 was present in higher amounts in oil and lecithin. The most significant saturated fatty acids were C16: 0 (26.14\%) and (20.20\%) in oil and lecithin, respectively. Linoleic acid and linolenic acid are essential fatty acids, these fatty acids were found in significant amount in shoul fish oil and linolenic acid was absent in fish lecithin. Another important polyunsaturated fatty acid arachidonic acid was $1.57 \%$ in fish oil.

\subsection{Oxidative Stability of Shoul Fish Lecithin}

The term oxidative stability refers to the susceptibility of a food or edible oil to lipid oxidation, which causes rancid odors and flavors. Oxidative stability may be used to provide information regarding the efficacy of antioxidants, the effect of impurities and evaluation of refining processes of fats and oils. The oxidative stability of shoul fish lecithin are shown in Fig 2A-B. In this study, the oxidation trend was evaluated instead of determining the absolute state of oxidation of the incubated sample. Lecithin with linoleic acid emulsions showed the increase in absorbance value from the first day. The increase in absorbance value was an indicator of auto-oxidation by formation of peroxides during incubation. Only the fish lecithin emulsion showed low absorbance values indicating low levels of lipid peroxidation until 15 days. The fish lecithin showed significantly increased oxidation after 20 days. In contrast, fish lecithin emulsions with $\beta$-carotene showed high oxidative stability. $\beta$-carotene, a strong antioxidant inhibited the peroxide formation of the lipids by peroxidation over a certain period. Initially, fish lecithin emulsion showed slightly higher absorbance as compared to lecithin within the linoleic acid emulsion. This might be due to the presence of peroxide from the oxidation of neutral lipids of fish lecithin. In thiobarbituric acid method, the absorbance measured on the $0,5,10,15$ th day was also similar to the lecithin and lecithin with $\beta$-carotene emulsions. However, this value was also high in the lecithin with linoleic acid emulsion indicating a low oxidative stability. On the other hand, a significant increase in absorbance was found on the 20th day of the lecithin emulsion sample. However, fish lecithin showed high oxidative stability. Lecithin from fish may contain small amounts of natural antioxidants that might be one of the causes of its higher oxidative stability [12]. [30] Gogolewski also reported that long chain polyunsaturated fatty acids which esterified with polar lipids had synergistic effects with antioxidants. High oxidative stabilities of lecithin from animal and plant sources were also reported by using different methods [16, 31-32].

Table 3. Fatty acid compositions (percent) of shoul fish oil and lecithin.

\begin{tabular}{|c|c|c|}
\hline \multirow{2}{*}{ Fatty acid compositions } & Shoul fish oil & Shoul fish lecithin \\
\hline & Fatty acid (\%) & Fatty acid (\%) \\
\hline Myristic acid (C14: 0) & 2.07 & N. D \\
\hline Myristoleic acid (C14: 1) & 0.91 & N. D \\
\hline Palmitic acid (C16: 0) & 26.14 & 20.2 \\
\hline Palmitoleic acid (C16: 1) & 4.67 & 3.80 \\
\hline Stearic acid (C18: 0) & 11.62 & 10.7 \\
\hline Oleic acid (C18: 1) & 26.97 & 15.0 \\
\hline Elaidic acid (18: 1) & 5.02 & 5.70 \\
\hline Linoleic acid (C18: 2) & 6.37 & 9.0 \\
\hline r-Linolenic acid (C18: 3 ) & 1.04 & N. D \\
\hline Arachidic acid (C20: 0) & 2.16 & N. D \\
\hline $\begin{array}{l}\text { cis-11,14-Eicosadienoic acid }+ \\
\text { Behenic acid (C20: } 2 \text { + C 22: } 0)\end{array}$ & 2.29 & N. D \\
\hline Linolenic acid (C18: 3) & 0.58 & N. D \\
\hline $\begin{array}{l}\text { Heneicosanoic acid + cis-11, } 14, \\
\text { 17-Eicosatrienoic acid (C21: } 0+ \\
\text { C20: } 3)\end{array}$ & 2.19 & N. D \\
\hline Tricosanoic acid (C23: 0) & 0.72 & 14.2 \\
\hline Arachidonic acid (C20: 4) & 1.57 & N. D \\
\hline $\begin{array}{l}\text { cis-8,11,14-Eicosatrienoic acid } \\
\text { (C20: 3) }\end{array}$ & 0.59 & N. D \\
\hline Erucic acid (C22: 1) & 2.14 & 13.7 \\
\hline $\begin{array}{l}\text { cis-13,16-Docosadienoic acid } \\
\text { (C22: } 2)\end{array}$ & 0.33 & N. D \\
\hline EPA (C20: 5) & 0.49 & N. D \\
\hline $\begin{array}{l}\text { Lignoceric acid + Nervonic acid } \\
(\mathrm{C} 24: 0+\mathrm{C} 24: 1)\end{array}$ & 0.76 & N. D \\
\hline DHA (C22: 6) & 1.37 & 7.8 \\
\hline
\end{tabular}

N. D: Not Detected. 


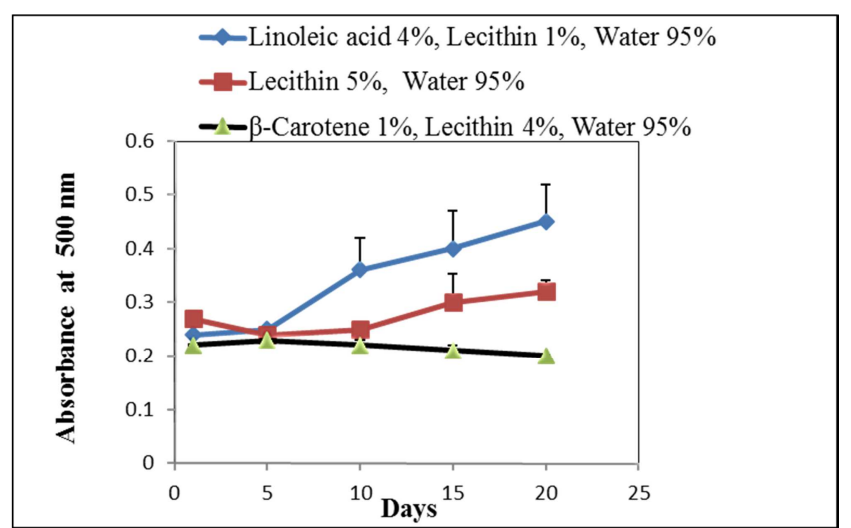

Figure 2-A. Measurement of oxidative stability of shoul fish lecithin by thiocyanate (TC) method and All data are presented by mean value of 3 replicate $\pm S D$ (SD was mentioned at least 0.01).

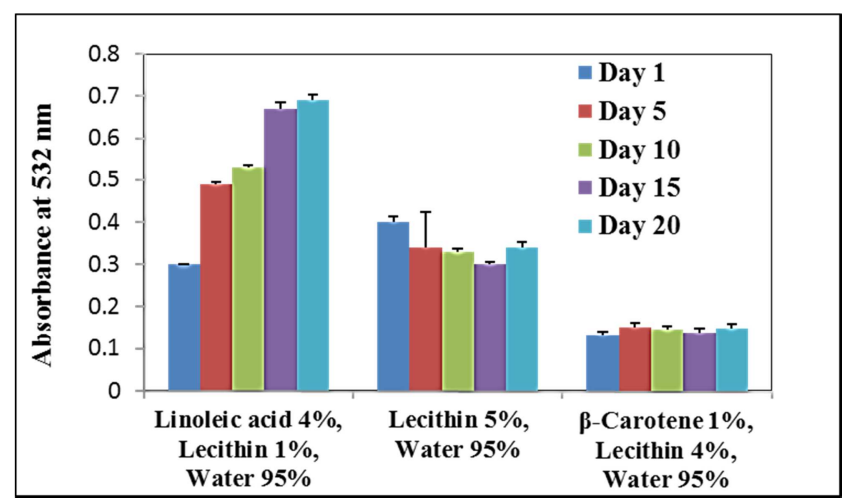

Figure 2-B. Measurement of oxidative stability of boal fish lecithin by thiobarbituric acid (TBA) method and All data are presented by mean value of 3 replicate $\pm S D$ (SD was mentioned at least 0.01 ).

\section{Conclusions}

In this study, oil and lecithin was isolated from shoul fish powder and characterized by measuring the iodine value, saponification value, FFA content, acid value, and peroxide value. The importance of lecithin analysis is to find the functional properties and fatty acid composition due to proper utilization of lecithin. Fatty acid composition of oil and lecithin was also measured by gas chromatography. Shoul fish oil and lecithin contain higher amount of unsaturated fatty acids (e. g, Palmitic acid, Stearic acid) which is used to produce soaps, cosmetics and release agents. Fish oil and lecithin is act as a source of essential fatty acid due to the presence of essential fatty acids. Shoul fish oil also contains arachidonic acid which is act as a precursor for prostaglandin synthesis. Shoul fish oil contains relatively high in monounsaturated fatty acids and an average in polyunsaturated fatty acid especially EPA and DHA. But EPA was not found in lecithin. The oxidative stability of oil and lecithin was also high due to the presence of natural antioxidant. Therefore, it can be concluded that shoul fish oil has the potential to be used as a local source of PUFA due to its comparatively high content of EPA and DHA. Lecithin can be used in pharmaceutical industry, cosmetic industry and also used as food additives and emulsifier.

\section{Acknowledgements}

The authors would like to thanks to the Laboratory of Advanced Processing Technology, Pukyong National University, Busan, South Korea.

\section{References}

[1] Roos, N., Islam M. M., and Thilsted S. H, Small Indigenous Fish Species in Bangladesh: Contribution to Vitamin A, Calcium and Iron Intakes, Research Department of Human Nutrition, The Royal Veterinary and Agricultural University, Frederiksberg, Denmark and Mymensingh Aquaculture Extension Project, Mymensingh, Bangladesh, 2003, Nutr. 133: 4021S-4026S.

[2] Kim, S. K., and Mendis S, Bioactive compounds from marine processing by products $-\mathrm{A}$ review Food Research International, 2006 39, 383-393.

[3] FAO/WHO. Rome, Food and Agriculture Organization of the United Nations; Geneva, World Health Organization. 2011.

[4] Farmer A, Montori V, Dinneen S, Clar C, 2004. Fish oil in people with type 2 diabetes mellitus. Cochrane Database Syst Rev (1): CD003205.

[5] Corrêa, A. P. A., Peixoto, C. A., Goncalves, L. A. G., Cabral, F. A, Fractionation of fish oil with supercritical carbon dioxide. Journal of Food Engineering 88, 381-387, 2008.

[6] Kris-Etherton, PM, et al. Fish consumption, fish oil, omega-3 fatty acids, and cardiovascular disease. Circulation. 106: 2747-57, 2002.

[7] Schmidt, EB, et al. Lipoprotein-associated phospholipase A2 concentrations in plasma are associated with the extent of coronary artery disease and correlate to adipose tissue levels of marine n-3 fatty acids. Atherosclerosis.; 196: 420-424, 2008.

[8] Din, JN, et al. Dietary intervention with oil rich fish reduces platelet-monocyte aggregation in man. Atherosclerosis.; 197: 290-296, 2008.

[9] Manirujjaman, M., Khan, M. M. H., Uddin, M., Islam, M., Rahman, M., Khatun, M., Biswas, S., and Islam, M. A, "Comparison of Different Nutritional Parameters and Oil Properties of Two Fish Species (Catla catla and Cirrhinus cirrhosus) from Wild and Farmed Sources Found in Bangladesh." Journal of Food and Nutrition Research, vol. 2, no. 1 (2014): 47-50. doi: 10.12691/jfnr-2-1-8.

[10] Lee, S. M., Asaduzzaman, A. K. M., and Chun, B. S, Characterization of Lecithin Isolated from Anchovy (Engraulis japonica) Residues Deoiled by Supercritical Carbon Dioxide and Organic Solvent Extraction, Journal of Food Science, 77 (7), 773-778, 2012.

[11] Brian, R. S., Michael, A., Sandoval, Andrew, M., Hau, He, H. Y., and Cui, Z, Strong Antibody Responses Induced by Protein Antigens Conjugated onto the Surface of Lecithin-Based Nanoparticles' Journal of Control Release. 4; 141 (1): 93-100. doi: 10.1016/j.jconrel, 2010.

[12] Uddin, M. S., Kishimura, H., and Chun, B. S, Isolation and Characterization of Lecithin from Squid (Todarodes pacificus) Viscera Deoiled by Supercritical Carbon Dioxide Extraction. Journal of Food Science _ Vol. 76, Nr. 2, C350-354, 2011. 
[13] Martin-Hernandez, C., Benet, S., Marvin-Guy, L. F, Characterization and quantification of proteins in lecithins. $\mathrm{J}$ Agric Food Chem 53: 8607-13, 2005.

[14] Amouni, M. M., Eder de, C. P., Priscila, G. M., Maricene, S., and Patricia, M, Influence of Soy Lecithin Administration on Hypercholesterolemia, Hindawi Publishing Corporation Cholesterol, Article ID 824813, 4 pages doi: 10.1155/2010/824813, Volume 2010.

[15] Sreedevi, T., Joseph, J., Devi, D. R., Hari, B. N. V, Isolation and characterization of lecithin from emu egg as novel pharmaceutical excipient, Rasāyan J. Chem, Vol. 5 | No.3 414-419 | July-September | 2012.

[16] Palacios, L. E., and Wang, T, Egg-yolk lipid fractionation and lecithin characterization. J Am Oil Chem Soc 82: 571-8, 2005.

[17] Suter, W., Jaeger, K. E., and Winkler, U. K, J. Bacteriol., 168, 50: 1721,1986

[18] Hanus Method, Animal and vegetable fats and oilsDetermination of iodine value, AOAC 920.158 ISO 3961: 199, 1966.

[19] IUPAC, Standard methods for the analysis of oils, Fats and Derivatives. $5^{\text {th }}$ Edition. Pergamon Press, Method-2. D. 7, P. $69,(1976 / 1977)$.

[20] AOCS, Official method and recommended practices of the AOCS, American Oil Chemists' Society, Volume I \& II. I II, 1998.

[21] Mitsuda, H., Yasumoto, K., and Iwami, K, Antioxidative action of indole compounds during the autoxidation of linoleic acid. Eiyo to Shokuryo 19: 210-4, 1966.

[22] Ottolenghi, A, Interaction of ascorbic acid and mitochondria lipids. Arch Biochem Biophy 79: 355-63, 1959.

[23] Molla, M. R., Asaduzzaman, A. K. M., Mia, A. R., Zeb, M. A., and Uddin, M. S., Extraction and characterization of oil and lecithin from boal (Wallago attu) fish, Journal of Food and Nutrition Research (Accepted).
[24] Shamsudin, S., and Salimon, J, Physicochemical characteristics of aji-aji fish Seriola nigrofasciata lipids, Malaysia Journal of Analytical Sciences, Vol 10: 55-58, 2006.

[25] Ambasankar K., and Balakrishnan V, Indian Sardine oil (Sardinelal longiceps) as a Source of Omega-3 Fatty Acids, Animal Nuu-izion and Feed Technoios, 6: 283-287, 2006.

[26] Paul, D. K., Islam, R., Sattar, M. A, Physico-chemical studies of Lipids and Nutrient contents of Channa striatus and Channa marulius, Turkish Journal of Fisheries and Aquatic Sciences 13: 487-493, ISSN 1303-2712 DOI: 10.4194/13032712-v13_3_11, 2013.

[27] Bako, T., Umogbai, V. I., and Obetta, S. E, Extraction and Characterization of Mackery (Scomber scombrus) Oil for Industrial Use. Researcher, 6 (8): 80-85, (ISSN: 1553-9865), 2014.

[28] Kadir, M. A., Abubakar, G. I., and Mohammed, A, Production and characterization of oil from fishes. Arpn Journal of Engineering and Applied Sciences VOL. 5, NO. 7 ISSN 18196608,2010

[29] FAO/WHO, Specification of identity and purity of sweetening agents, emulsifying agents, flavouring agents and other food additives, 24 March to 2 April, 1980, Page no. 67. [Web address:

https://books. google.com.bd/books?hl=en\&lr=\&id=J2hRivQz gBMC\&oi $=$ fnd\&pg $=$ PR1\&dq $=$ purity + of + lecithin + by $+F A O /$ WHO\&ots $=F g A 46 r$ jd $4 \&$ sig $=87$ ulHevJmgJeEYr06cdWKLB 4apg\&redir_esc $=\mathrm{y} \# \overrightarrow{\mathrm{v}}=$ onepage.

[30] Gogolewski, M., Nogala-Kalucka, M., and Szeliga, M, Changes of the tocopherol and fatty acid contents in rape seed oil during refining. Eur J Lipid SciTechnol 102: 618-23, 2000.

[31] Wang, G., and Wang, T, Oxidative stability of egg and soy lecithin as affected by transition metal ions and $\mathrm{pH}$ in emulsion. J Agric Food Chem 56: 11424-31, 2008.

[32] Belhaj N, Arab-Tehrany, E., and Linder, M, Oxidative kinetics of salmon oil in bulk and in nanoemulsion stabilized by marine lecithin, Process Biochem 45: 187-95, 2010. 